\title{
The Development Of The Electronic Nursing Record System (ENRS) In The Hospital Setting: An Integrative Literature Review
}

Rini Rachmawaty, Hasanuddin University, Indonesia

\begin{abstract}
In Indonesian hospitals, particularly in South Sulawesi Province, one of the activities that needs improvement by design is that of nursing records. This vital task is not completed due mainly to the fact that, incredibly, no model has been implemented to date mainly because of financial constraints and the overall lack of nurses' computer literacy within the health services area in Indonesia. Although copious nursing recordkeeping is standard practice abroad, this vital task is not the norm in our area. Thus, the aim of this integrative literature review was to investigate the development of the electronic nursing record system (ENRS) in hospital settings across different countries and its effects on the care process and care outcomes. The results of this review showed that ENRS has been used widely in other developed countries and has benefited nurses and other healthcare providers. Hence, the findings of this review can be used by hospital policymakers in other developing countries, where the ENRS have not been implemented yet, as the evidence to consider the use of the ENRS.
\end{abstract}

Keywords: Electronic Nursing Record System; Nursing Documentation; Quality Of Care

\section{INTRODUCTION}

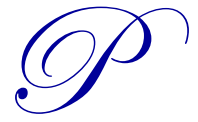

an American Health Organization (2000, p. 21) defined nursing documentation as, "the evidence that the nurse's legal and ethical responsibilities to the patient were met and that the patient received care of acknowledged quality." The format of this record has varied over time amongst different specialties and different countries. Nurses have considered the urgency of this nursing record as means to communicate with other health staffs and to promote the patient safety and the continuity of care (Urquhart, Currell, Grant, \& Hardiker, 2009).

In Indonesia, most hospitals apply the manual nursing care planning. In the implementation of this documentation, nurses are obliged to record all patient intervention by writing a large amount of paperwork. However, the design of this paperwork is not nationally standardized since lack of nursing research focused on this issue. Hence, different hospitals apply different paper-based nursing records leading to various interpretations of the importance of nursing records.

In South Sulawesi, Indonesia, most hospitals use paper-based nursing records. There are, however, several drawbacks to this approach (Hikmawaty, 2009; Salama, 2009; Widiastuti, 2009) and one hospital that launched an electronic nursing record had significant problems (Maemunah, 2009). Based on clinical observations, currently nurses only record patients' vital signs and medications administered; however, there are numerous significant things not documented; for example, fluid balance for 24 hours, wound dressing changes, daily wound conditions and other significant nursing practices. There are a number of reasons for this problem. First of all, the paper-based nursing record is not systematic and leads nurses to write copious notes. Moreover, the software design of the electronic nursing record does not cover all patients' conditions, nurses are not familiar with the computer, and the 
data on the computer cannot be accessed directly by other health professionals. Therefore, the quality of care given by those health professionals is low due to lack of interaction amongst them.

The weaknesses of the paper-based nursing record system were also reported by some researchers in their papers. Daly, Buckwalter, and Maas (2002) found that whilst using the paper-based system, the nurses did not record all the care that was actually given. Similarly, Ammenwerth et al. (2001) discovered that illegibility of handwriting, incompleteness of data and inaccessibility of information were the main shortfalls of paper-based nursing documentation. Since the manual nursing record was inaccurate, differences in quality and frequency of records, along with omitted data, limited the utilization of patient data (Cho \& Park, 2003). Redundancy of information was also found in the paper-based nursing record system, resulting in large volumes of paper managed and stored. This led to unnecessary time-consuming searching for patient's information (Ayatollahi, Bath, \& Goodacre, 2009).

All the aforementioned issues contribute to the ineffectiveness of the current nursing recording system and affect the whole healthcare system. Several studies conducted in the developed countries (i.e., European countries, USA, Canada, Australia, Japan, South Korea, and Taiwan) found that the application of the computerized nursing record is more effective than the antiquated and inefficient manual nursing record system. According to Ayatollahi et al. (2009) and Bosman et al. (2003) using the electronic nursing record system increased the speed of processes, avoided duplication, improved access to patients' notes, facilitated work that led nurses to have more time for patient care, and improved the clinical decision-making. It was also perceived as a means to reducing clinical errors as it showed legible text while providing accurate data. Thus, Ammenwerth et al. (2001) and Mahler et al. (2007) concluded that the implementation of the electronic nursing record system increased the quantity and quality of documentation and improved communication between healthcare professionals.

\section{OBJECTIVE}

This paper will investigate the development of the electronic nursing record system (ENRS) in hospital settings across different countries and its effects on the care process and care outcomes. Throughout this review is discussed the ENRS design (i.e., content), the computer use, the effects of the ENRS, and the challenges to develop this system.

\section{METHOD}

A comprehensive literature search was conducted to produce an explicit literature review and the references used for this integrative literature review were published papers from 1980 to 2010 in order to trace the initial use of the electronic nursing record system. The inclusion criteria for the literature were: (1) written in English; (2) the differences between the paper-based record and the electronic nursing record system, as discussed; (3) the electronic nursing record, the design, and the challenges in developing it as described; and (4) studies conducted in hospital settings. Six electronic databases (CINAHL, PubMed, OVID Medline, Google Scholar, Cochrane Library, and RefWorks) searched the literature and using the related articles provided in the database (i.e., PubMed) for searching relevant papers. The keywords were electronic nursing record system and nursing records. A total of 24 articles were included in this review.

\section{FINDINGS}

\section{The Electronic Nursing Record System (ENRS)}

Urquhart et al. (2009) described the electronic nursing record system (ENRS) as the digital form of nursing records that contains all significant information about the patient status and intervention that is planned and provided by registered nurses or other care givers (including nursing students) under the control of a competent nurse.

In the essence of the development of the ENRS, it is vital to primarily understand the evolution of nursing records. One of the first important characters to realize the importance of detailed nursing notes was Florence 
Nightingale in 1854 whilst she cared for severely traumatized patients in the Crimean War. In the 1960s, the first computer software for nursing care was introduced in the U.S. and continued to be technologically advanced in the 1980's (Stevenson, Nilsson, Petersson, \& Johansson, 2010). In the 1990s, the electronic nursing record replaced the manual nursing record and the evaluation of the new system was taken from 2000 to 2004 (Hayrinen, Saranto, \& Nykanen, 2008). In the last five years, the tendency of nursing informatics research was on the content of the electronic nursing record system. This trend was mainly influenced by the advancement of technology in healthcare and the action to realize the health reform in some countries (Abbott \& Coenen, 2008).

\section{A Theoretical Framework And The Content Of The ENRS}

Park, Cho, and Byeun (2007) conducted a study that depicted the framework used for developing the ENRS and the content of the system. In their framework, a standard terminology was used to model nursing information (see Appendix). Nursing process-assessment, problem/diagnosis, care plan, activity, and evaluation were captured and expressed in the content of nursing records. A terminology server of the model managed three types of controlled terminology - clinical, administrative, and reference. Clinical terminology contained the Nursing Minimum Data Set (NMDS) that comprised nursing care elements, patient demographic elements, and service elements. Meanwhile, in administrative terminology, the NANDA Taxonomy, the Clinical Care Classification, and the Nursing Interventions Classification (NIC) were used to analyze and summarize the clinical data in the repository of an ENRS. Finally, the International Classification of Nursing Practice (ICNP) beta version was used as the reference terminology that consisted of three data categories - nursing diagnosis, nursing activities, and nursing outcomes (Baernholdt \& Lang, 2003).

In addition to the design of the ENRS, some researchers from other countries established framework models for the ENRS based on their healthcare system. In Switzerland, the Nursing Service Commission of Department of Health launched the Electronic Nursing Process Data Model (ENPDM) as a framework to design the ENRS. In this model, they developed the Swiss NMDS and integrated the NANDA, NIC and Nursing Outcomes Classification (NOC) terminologies into the electronic patient record (Bernhart-Just, Lassen, \& Schwendimann, 2010). Similarly, Volrathongchai, Delaney, and Phuphaibul (2003) created the Thai NMDS that was considered more appropriate to the Thailand healthcare environment. In the Thai NMDS, there were some aspects of patient elements that were added, while some information in the service elements was omitted compared to the U.S. NMDS developed by Werley and Lang in 1988. Turning to the ENRS in Finland, this country had set up the Finnish model of standardized nursing documentation that used the terminologies that focused more on the neurological and surgical settings (Hayrinen, Lammintakanen, \& Saranto, 2010).

\section{Computer Use For The ENRS}

Regarding the most appropriate type of computer for the ENRS, Carlson et al. (2010) evaluated the use of point-of-care devices - stationary personal computers, workshops on wheels, and hand-held tablets in relation to the timeliness of data entry and staff preferences. From their study, they found that the hand-held tablets were the best devices in terms of timeliness of data entry compared to other devices. Moreover, the staff preferred to utilize it as it promoted eye contact with the patient. Even so, the stationary personal computers and workshops on wheels were perceived to be more effective for charting and medication administration, respectively.

\section{The Effects Of The ENRS}

In terms of the advantages and disadvantages of the ENRS, some researchers examined the effects of this system on the time investment for documentation, the quality of documentation, the user acceptance, the time spent for searching information, and the quality of care. Ammenwerth et al. (2001) and Bosman et al. (2003) found that the ENRS had lower time investment in documenting the nursing care plan but had higher time spent in recording the tasks and writing the report than the paper-based nursing record system. The quality of documentation was also high in the use of the ENRS while low in time spent for searching patients' information (Ammenwerth et al., 2001; Ayatollahi et al., 2009). In the light of user acceptances, nurses and doctors showed positive attitudes toward the use of the ENRS as long as they were involved in designing and implementing the ENRS and prepared with the training (Ayatollahi et al., 2009; Choi, Chung, \& Lee, 2006). Regarding the quality of care, the use of ENRS had decreased the hospital-wide mortality rate by $20 \%$ (Longhurst et al., 2010). 


\section{Challenges In Developing The ENRS}

Ayatollahi et al. (2009) classified the challenges in advancing the ENRS into two categories - technical and non-technical. Systems integration, interface design, ease of use, usefulness, and system functions were included in the technical challenges. Meanwhile, the non-technical challenges comprised the communication with system developers, user involvement, change management, and training. Additionally, Helleso and Ruland (2001) highlighted the organizational and professional challenges in the development of the ENRS. In terms of the organizational challenges, the role of nurse managers is considered vital in maintaining and improving the use of the ENRS. Moreover, cultural resistance is predicted as an inevitable barrier and thus, optimal acceptance must be obtained prior to the implementation of the ENRS. Turning to the professional challenges, the standardized and formalized language were required in the development and implementation of electronic nursing documentation. Therefore, the NMDS and terminologies used in the content of the ENRS must be internationally recognized.

\section{Limitations, Gaps, And Strengths Of Integrative Group Of Studies}

Limitations of integrative group of studies were notified during the literature review. Some studies used self-assessment methods that might lead to research biases, mainly the testing effect. For some research, the sample size was not adequate and the setting of the study was conducted in the specific unit or ward. These conditions resulted in the inadequacy of research findings to be generalized into other areas. Another limitation was only one study conducted in Southeast Asia (i.e., Thailand) - not a research article, but a literature review. Thus, in the future, the development of the ENRS in developing countries needs to be studied.

The first gap in the literature, which was identified as future research, is required to study the effect of the ENRS for patient safety pre and post using the standardized terminology-based ENRS. Other gaps were the impact of the ENRS on the outcome quality by utilizing longitudinal studies and identifying which characteristics of nursing practice are best served by the ENRS.

Strengths of trends across studies were identified, such as the research design, method, area of interests, and location of the studies. Most studies used quantitative design, but the methods were mixed methods (e.g. interview, questionnaires, observation $\&$ documentation analysis). The research focused more on the structure and process quality than the outcome quality as it was difficult to measure the care outcome. Most studies were conducted in developed countries.

\section{CONCLUSION}

The creation of the computerized nursing care system is vital for the improvement of quality of care in all countries as it reduces the time for documenting, whilst enhancing patient care. Even so, a well-designed and standardized ENRS and the optimal acceptance from all care providers is required prior to implementation of this system.

In this review, several research findings recommended the development of the ENRS content (i.e., NMDS) based on the country's healthcare system. Nevertheless, the administrative and reference terminologies used in that ENRS must be internationally standardized. Otherwise, the ENRS may not be used as a media for communication amongst health professionals across different countries.

\section{AUTHOR INFORMATION}

Dr. Rachmawaty is a lecturer at the School of Nursing, Faculty of Medicine, Hasanuddin University, Makassar, Indonesia. She obtained her Bachelor of Science in Nursing and Professional Nurse from University of Indonesia in 2002 and 2003, respectively. In 2008, she attained her Master of Nursing-Management from the University of Technology Sydney, Australia, sponsored by the Australian Partnership Scholarships. Finally, in 2014, she obtained her PhD degree in nursing from the School of Nursing University of Virginia, United States, sponsored by Fulbright Presidential Scholarships. Her research interest is in nursing management mainly focused on healthcare quality, electronic health records, and diabetes. Email address: rr7bz@ virginia.edu 


\section{REFERENCES}

Abbott, P. A., \& Coenen, A. (2008). Globalization and advances in information and communication technologies: The impact on nursing and health. Nursing Outlook, 56(5), 238-246.

Ammenwerth, E., Eichstadter, R., Haux, R., Pohl, U., Rebel, S., \& Ziegler, S. (2001). A randomized evaluation of a computerbased nursing documentation system. Methods of Information in Medicine, 40, 61-8.

Ayatollahi, H., Bath, P. A., \& Goodacre, S. (2009). Paper-based versus computer-based records in the emergency department: Staff preferences, expectations, and concerns. Health Informatics Journal, 15(3), 199-211.

Baernholdt, M., \& Lang, N. M. (2003). Why an ICNP? Links among quality, information and policy. International Nursing Review, 50, 73-78.

Bernhart-Just, A., Lassen, B., \& Schwendimann, R. (2010). Representing the nursing process with nursing terminologies in electronic medical record systems: A Swiss approach. Computers, Informatics, Nursing: CIN, 28(6), 345-352.

Bosman, R. J., Rood, E., Oudemans-Van Straaten, H., Van der Spoel, J. I., Wester, J. P. J., \& Zandstra, D. F. (2003). Intensive care information system reduces documentation time of the nurses after cardiothoracic surgery. Intensive Care Medicine, 29, 83-90.

Carlson, E., Catrambone, C., Oder, K., Nauseda, S., Fogg, L., Garcia, B., Brown, F. M., Jr., Johnson, M. E., Johnson, T. J., \& Llewellyn, J. (2010). Point-of-care technology supports bedside documentation. The Journal of Nursing Administration, 40(9), 360-365.

Cho, I., \& Park, H. A. (2003). Development and evaluation of a terminology-based electronic nursing record system. Journal of Biomedical Informatics, 36(4-5), 304-312.

Choi, E. Y., Chung, E. J., \& Lee, H. S. (2006). Users' satisfaction on the electronic nursing record system. Studies in Health Technology and Informatics, 122, 855.

Daly, J. M., Buckwalter, K., \& Maas, M. (2002). Written and computerized care plans. Organisational processes and effect on patient outcomes. Journal of Gerontological Nursing, 28(9):14-23.

Hayrinen, K., Saranto, K., \& Nykanen, P. (2008). Definition, structure, content, use and impacts of electronic health records: A review of the research literature. International Journal of Medical Informatics, 77, 291-304.

Hayrinen, K., Lammintakanen, J., \& Saranto, K. (2010). Evaluation of electronic nursing documentation--nursing process model and standardized terminologies as keys to visible and transparent nursing. International Journal of Medical Informatics, 79(8), 554-564.

Helleso, R., \& Ruland, C. M. (2001). Developing a module for nursing documentation integrated in the electronic patient record. Journal of Clinical Nursing, 10, 799-805.

Hikmawaty. (2009). Asuhan keperawatan [Nursing care]. Makassar, Indonesia: Hasanuddin University: Hospital Management Program.

Longhurst, C. A., Parast, L., Sandborg, C. I., Widen, E., Sullivan, J., Hahn, J. S., . . ., Sharek, P. J. (2010). Decrease in hospitalwide mortality rate after implementation of a commercially sold computerized physician order entry system. Pediatrics, 126(1), 14-21.

Maemunah. (2009). Pendokumentasian asuhan keperawatan di RSUP Dr. Wahidin Sudirohusodo Makassar [Documentation of nursing care in Dr. Wahidin Sudirohusodo hospital Makassar]. Makassar, Indonesia: Hasanuddin University: Hospital Management Program.

Mahler, C., Ammenwerth, E., Wagner, A., Tautz, A., Happek, T., Hoppe, B., \& Eichstadter, R. (2007). Effects of a computerbased nursing documentation system on the quality of nursing documentation. Journal of Medical Systems, 31, $274-82$.

Pan American Health Organization. (2000). Building Standard-Based Nursing Information Systems. Washington, D.C.: PAHO.

Park, H. A., Cho, I., \& Byeun, N. (2007). Modeling a terminology-based electronic nursing record system: An object-oriented approach. International Journal of Medical Informatics, 76(10), 735-746.

Salama, U. (2009). Analisa dokumentasi asuhan keperawatan RSUD Syekh yusuf Kabupaten Gowa [Analysis of nursing care documentation in Syekh Yusuf hospital, Gowa regency]. Makassar, Indonesia: Hasanuddin University: Hospital Management Program.

Stevenson, J. E., Nilsson, G. C., Petersson, G. I., \& Johansson, P. E. (2010). Nurses' experience of using electronic patient records in everyday practice in acute/inpatient ward settings: A literature review. Health Informatics Journal, 16(1), 63-72.

Urquhart, C., Currell, R., Grant, M. J., \& Hardiker, N. R. (2009). Nursing record systems: Effects on nursing practice and healthcare outcomes. Cochrane Database of Systematic Reviews, (1), 002099.

Volrathongchai, K., Delaney, C. W., \& Phuphaibul, R. (2003). Nursing Minimum Data Set development and implementation in Thailand. Journal of Advanced Nursing, 43(6), 588-594.

Widiastuti, J. (2009). Analisa dokumentasi asuhan keperawatan ruang rawat inap lantai II.A RS. Pelamonia Makasar [Analysis of nursing care documentation in II.A inpatient ward, Pelamonia hospital, Makassar]. Makassar, Indonesia: Hasanuddin University: Hospital Management Program. 


\section{APPENDIX}

Nursing Information Model For An Electronic Nursing Record System (ENRS)

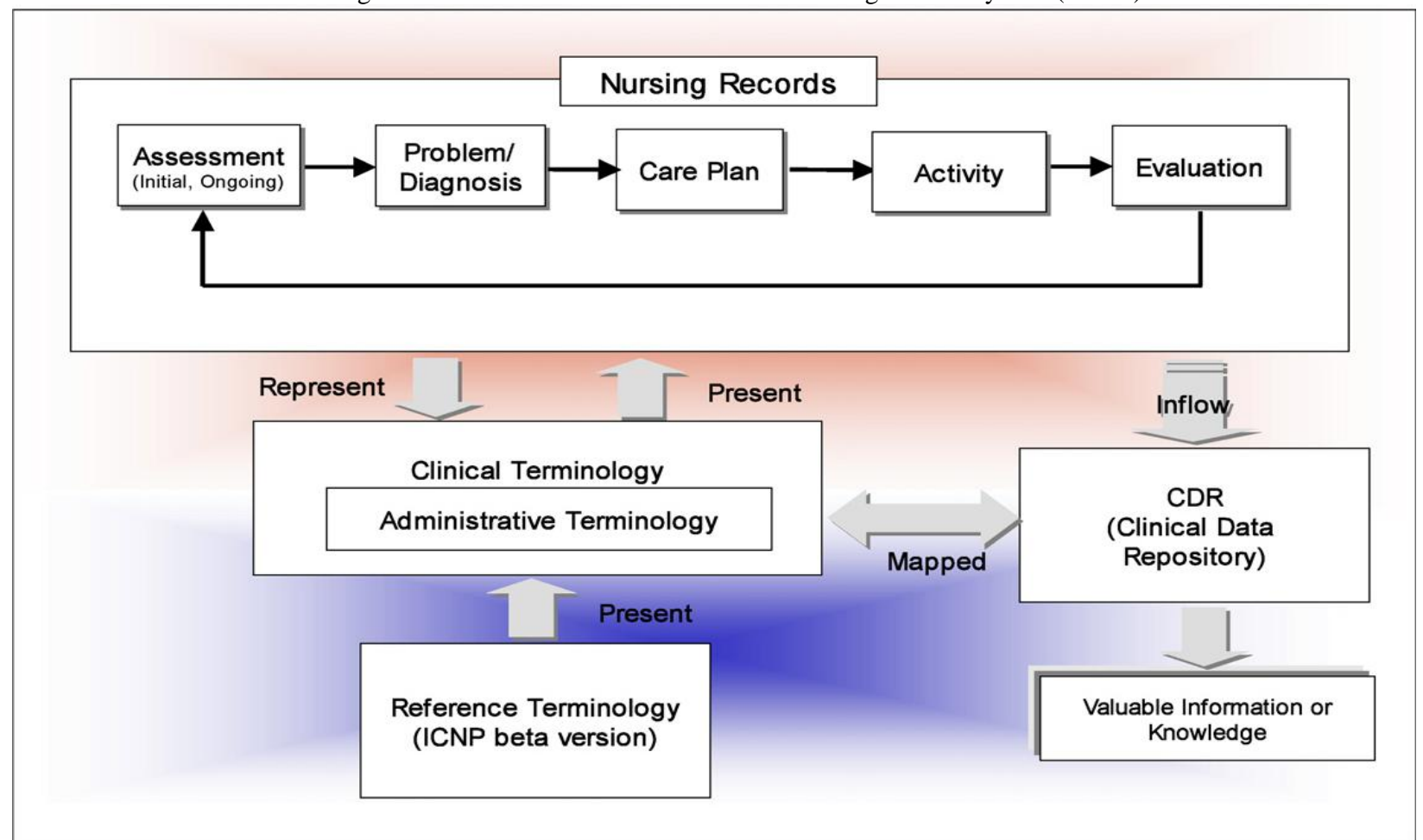

Source: Park, H. A., Cho, I., \& Byeun, N. (2007). Modeling a terminology-based electronic nursing record system: An objectoriented approach. International Journal of Medical Informatics, 76(10), 735-746. 